\title{
LXR agonist T0901317 upregulates thrombomodulin expression in glomerular endothelial cells by inhibition of nuclear factor- $\kappa B$
}

\author{
HANLU DING $^{1 *}$, YI LI $^{1 *}$, YUNLIN FENG ${ }^{1}$, JIN CHEN $^{1}$, XIANG ZHONG ${ }^{1}$, \\ NAN WANG $^{2}$, WEI WANG ${ }^{1}$, PING ZHANG ${ }^{1}$ and LI WANG $^{1}$ \\ ${ }^{1}$ Department of Nephrology, University of Electronic Science and Technology, Sichuan Academy of Sciences, \\ Sichuan Provincial People's Hospital, Chengdu, Sichuan 610072; ${ }^{2}$ Department of Nephrology, \\ Chengdu Second People's Hospital, Chengdu, Sichuan 610041, P.R. China
}

Received May 16, 2015; Accepted January 25, 2016

DOI: $10.3892 / \mathrm{mmr} .2016 .5138$

\begin{abstract}
Dysfunction of glomerular endothelial cells (GECs) induces a variety of symptoms, including proteinuria, inflammation, vascular diseases, fibrosis and thrombosis. Thrombomodulin (TM) acts as a vasoprotective molecule on the surface of the vascular endothelial cells to maintain the homeostasis of the endothelial microenvironment by suppressing cellular proliferation, adhesion and inflammatory responses. Liver X receptor (LXR), a nuclear receptor (NR) and a bile acid-activated transcription factor, regulates metabolism and cholesterol transport, vascular tension and inflammation. Previous studies indicated that TM expression is upregulated by various NRs; however, it is unclear whether pharmacological modulation of LXR may affect TM expression and GEC function. The current study revealed that LXR activation by its agonist, T0901317, upregulates the expression and activity of TM. This effect was mediated specifically through LXR- $\alpha$, and not through LXR- $\beta$. Additionally, T0901317 treatment inhibited nuclear factor $-\kappa \mathrm{B}(\mathrm{NF}-\kappa \mathrm{B})$ signaling and the secretion of high glucose-induced proinflammatory mediators, including tumor necrosis factor- $\alpha$ and interleukin- $1 \beta$ in GECs. Co-immunoprecipitation experiments determined that treatment with T0901317 enhances the interaction between LXR- $\alpha$ and the transcriptional coactivator, p300, in GEC extracts. The present findings suggest that $\mathrm{NF}-\kappa \mathrm{B}$ may be a negative regulator of TM expression, and its removal may contribute to TM gene expression, particularly when in competition with the T0901317-enhanced formation of the
\end{abstract}

Correspondence to: Dr Li Wang, Department of Nephrology, University of Electronic Science and Technology, Sichuan Academy of Sciences, Sichuan Provincial People's Hospital, 1 Ring Road, Qingyang, Chengdu, Sichuan 610072, P.R. China

E-mail: brittnayli@126.com

*Contributed equally

Key words: liver $\mathrm{X}$ receptor, glomerular endothelial cells, nuclear factor- $\kappa \mathrm{B}$, thrombomodulin
LXR/p300 complex. Therefore, LXR may be a novel molecular target for manipulating TM in GECs, which may advance the treatment of endothelial cell-associated diseases.

\section{Introduction}

The inflammatory responses of glomerular endothelial cells (GECs) lead to proteinuria; however, the underlying mechanism has yet to be fully elucidated (1). Thrombomodulin (TM), a type I membrane-bound glycoprotein, is ubiquitously expressed in vascular endothelial cells (VECs) and is a potential suppressor of inflammatory processes (2). Thus, upregulation of TM expression and/or function may be a potential therapy for inflammation-induced microvascular diseases, including proteinuria (2). The potential therapeutic value of TM modulation motivated the search for naturally abundant compounds that may regulate this vasoprotective molecule. Notably, previous studies determined that various nuclear receptors (NRs) were involved in the regulation of TM expression (3-5). However, the regulatory mechanism underpinning TM expression has yet to be fully elucidated.

Liver X receptors (LXRs) are important regulators of cholesterol, free fatty acids and glucose metabolism $(6,7)$. In addition to their importance in lipid and glucose metabolism, the activation of LXR was also reported to be of high importance in regulating immune processes and in inhibiting inflammatory gene expression (8-12). LXRs are ligand-activated transcription factors of the nuclear receptor superfamily. There are two LXR isoforms, termed LXR- $\alpha$ and LXR- $\beta$. Upon activation, they form heterodimers with retinoid $\mathrm{X}$ receptor and bind to the LXR response element located in the promoter region of the target genes (13). Previous studies have determined that TM may improve diabetic nephropathy (DN) via anti-nuclear factor- $\kappa \mathrm{B}(\mathrm{NF}-\kappa \mathrm{B}) / \mathrm{NLR}$ family pyrin domain containing 3 inflammasome-mediated inflammation or via complement inhibition $(14,15)$. Full transcriptional activity of $\mathrm{NF}-\kappa \mathrm{B}$ requires physical interaction with the closely associated transcriptional coactivators, p300 and cAMP response element binding protein (CREB1) $(16,17)$. In addition, inflammation is also reported to regulate the development of DN (16). Thus, seeking effective targets to ameliorate inflammation of human GECs (HUGECs) 
may provide a promising strategy to reduce the secretion of urinary proteins.

In addition to the importance of LXRs in lipid and glucose metabolism, synthetic LXR agonists have been determined to inhibit inflammation in various animal models, including pulmonary inflammation (18). A previous study has reported that LXRs may antagonize the cytokine-mediated expression of proinflammatory genes in macrophages via the silencing of proinflammatory transcription factors, particularly $\mathrm{NF}-\kappa \mathrm{B}$ (19). Cheng et al (20) determined that LXR activation may inhibit the transcription of various inflammatory genes, including tumor necrosis factor (TNF), cytochrome $c$ oxidase subunit II, interleukin-1 $\beta$ (IL-1 $\beta$ ), matrix metallopeptidase 9 and inducible nitric oxide synthase. Although they share similar anti-inflammatory functions and location of expression in endothelial cells, the association between LXR and TM remains to be fully elucidated $(21,22)$.

In the present study, the expression and activity of TM were demonstrated to be upregulated by the LXR agonist, T0901317, in HUGECs. Luciferase reporter assays indicated no effect of LXR on the activity of the TM promoter $(-2,494$ to +160 bp). However, activating LXR effectively inhibited I $\mathrm{B}$ phosphorylation and p65 translocation in HUGECs. LXR activation enhanced the interaction between LXR and p300, which is a physical partner with NF- $\kappa \mathrm{B}$ in HUGEC extracts, as indicated by western blotting and co-immunoprecipitation analyses. The current findings suggest that $\mathrm{NF}-\kappa \mathrm{B}$ may be a negative regulator of TM expression, and that LXR activation may indirectly modulate TM expression via inhibition of $\mathrm{NF}-\kappa \mathrm{B}$ activation and/or restricting its availability for the formation of the LXR/p300 complex.

\section{Materials and methods}

Reagents. T0901317 (a specific synthetic ligand agonist for LXR) was purchased from Sigma-Aldrich (T2320; St. Louis, MO, USA). Pierce BCA Protein Assay Reagent B kit was obtained from Thermo Fisher Scientific, Inc. (cat. no. 23224; Waltham, MA, USA). Lipofectamine 2000, TRIzol ${ }^{\circledR}$ and all reagents for cell culture procedures were purchased from Invitrogen; Thermo Fisher Scientific, Inc. (cat. no. 11668-019). Argatroban was obtained from Tianjin Pharmaceuticals Research Institute Co., Ltd. (Tianjin, China). D-Mannitol and D-glucose (cat. nos. M8140 and G8270) were sourced from Beijing Solarbio Science \& Technology Co., Ltd. (Beijing, China).

Cell culture. The primary human glomerular endothelial cell line was purchased from ScienCell Research Laboratories (cat. no. 4000; Carlsbad, CA, USA) and cultured in Dulbecco's modified Eagle's medium with $10 \%$ fetal bovine serum (FBS), $100 \mathrm{U} / \mathrm{ml}$ penicillin and $100 \mu \mathrm{g} / \mathrm{ml}$ streptomycin. Prior to being treated with T0901317, the cells were cultured in Opti-MEM medium (Thermo Fisher Scientific, Inc.) supplemented with $0.5 \%$ FBS (conditioned medium). All experiments performed with HUGECs were performed at passages 4-6. The cells were grown on $0.2 \%$ gelatin-coated plates (Corning, Inc., Wiesbaden, Germany) and maintained at $37^{\circ} \mathrm{C}$ in a humidified $5 \% \mathrm{CO}_{2}$ incubator using endothelial cell medium (ScienCell Research Laboratories, Carlsbad, CA, USA; cat. no. 1001).
Cells were subcultured at confluence by trypsinization with $0.05 \%$ trypsin and $0.02 \%$ EDTA. The medium was changed every other day.

Construction of recombinant adenoviruses. The $72 \mathrm{nt}$ oligonucleotide encoding mouse TM small interfering (si) RNA was inserted into the BamHI and EcoRI sites of pHBAd-U6-GFP to build the pHBAd-U6-GFP-siRNA/TM shuttle plasmid. The resultant shuttle plasmid was identified by double restriction-enzyme digestion and DNA sequencing was conducted by Shanghai Sunny Biotech Co., Ltd. (Shanghai, China). The shuttle plasmid was then co-transfected with a backbone plasmid [pBHGlox $(\Delta) \mathrm{E} 1,3 \mathrm{Cre}$ ] into HEK293 cells (CRL12108; American Type Culture Collection, Manassas, VA, USA) as described below. The expression of the TM protein in the infected endothelial cells was detected by western blot analysis. A control adenovirus (Vector Biolabs, Malvern, PA, USA; cat. no. 1060) containing the green fluorescence protein (GFP) gene (Ad.GFP) was generated, purified, titrated, and stored as described previously (23).

Transfection. Cells were seeded into $25 \mathrm{~cm}^{2}$ flasks and were cultured until $>60 \%$ confluent. HUGECs were successfully transfected withLXR- $\alpha$ shRNA and treated with $2 \mu$ MT0901317 for $24 \mathrm{~h}$. Cells were then exposed to $25 \mathrm{mM}$ glucose or $25 \mathrm{mM}$ mannitol for $6 \mathrm{~h}$. The recombinant adenovirus transfection was performed following the protocol described in a previous study (24). LXR- $\alpha$ and LXR- $\beta$ siRNAs were obtained from Invitrogen; Thermo Fisher Scientific, Inc. Cells were washed once with OptiMEM medium, $2.5 \mathrm{ml}$ OptiMEM medium was added to each flask, and subsequently these flasks were placed in an incubator at $37^{\circ} \mathrm{C}$ for $30 \mathrm{~min}$ prior to transfection. A transfection mix was prepared by adding $4 \mu \mathrm{g}$ recombinant adenovirus plasmid DNA and $20 \mu 1$ Lipofectamine 2000 to $500 \mu \mathrm{l}$ OptiMEM medium, according to manufacturer's protocol. For gene silencing, cells were seeded into 6-well plates and were cultured until $>75 \%$ confluent. The cells were transiently transfected with $25 \mathrm{nmol} / \mathrm{l}$ LXR- $\alpha$ siRNA, LXR- $\beta$ siRNA or negative control siRNA (scrambled siRNA) using Lipofectamine 2000 transfection reagents, according to the manufacturer's protocol. After $24 \mathrm{~h}$, fluorescence images of transfected cells were observed under a Nikon T300 fluorescence microscope (Nikon Corporation, Tokyo, Japan).

Reverse transcription-quantitative polymerase chain reaction $(R T-q P C R)$. Total RNA $(2 \mu \mathrm{g})$ was extracted from HUGECs using the TRIzol reagent (Takara Bio, Inc., Otsu, Japan), according to the manufacturer's protocol. The first-strand cDNA was synthesized using Moloney murine leukemia virus reverse transcriptase (Toyobo Co., Ltd., Osaka, Japan) and an oligo (dT) primer. The expression levels of human TM and human small ATP-binding cassette transporter A1 (ABCA1), a target gene of LXR, were examined using RT-qPCR, which was performed using the Bio-Rad iQ5 Gradient Real Time PCR system with SYBR Premix Ex Taq II kit (Takara Bio, Inc.; cat. no. RR820A) according to the manufacturer's protocol in a $20 \mu \mathrm{l}$ volume in triplicate. Briefly, $10 \mu \mathrm{l}$ SYBR Green were mixed with $0.3 \mu 1$ reverse primer and $2 \mu \mathrm{l}$ cDNA. The cycle parameters performed were as follows: $94^{\circ} \mathrm{C}$ for $5 \mathrm{~min}$, 40 cycles at $94^{\circ} \mathrm{C}$ for $30 \mathrm{sec}, 57^{\circ} \mathrm{C}$ for $30 \mathrm{sec}$ and $72^{\circ} \mathrm{C} 30 \mathrm{sec}$, 
and $72^{\circ} \mathrm{C}$ for $10 \mathrm{~min}$. The primers used for $\mathrm{TM}$ and $\mathrm{ABCA} 1$ were as follows: i) TM (173 bp), forward (F), 5'-CGGGCT CCTACTCGTGCATG-3'; reverse (R), 3'-GCCGTCCACCAG GTCGTAGTTA-5'; and ii) ABCA1 (100 bp), F, 5'-ATGTCC AGTCCAGTAATGGTTCTGT-3, R, 3'-CGAGATATGGTC CGGATTGC-5'. As an internal control, $\beta$-actin (527 bp) was analyzed in parallel by using the following primers: F, 5'-CTA CAATGAGCTGCGTGTGG-3', R, 3'-AAGGAAGGCTGG AAGAGTGC-5'. The $\mathrm{C}_{\mathrm{q}}$ value, which is inversely proportional to the initial template copy number, was the calculated cycle number at which the emitted fluorescence signal was first significantly higher than the background levels. The separate well $2^{-\Delta \Delta C q}$ cycle quantification method was used to determine relative quantitative levels of TM and ABCA1, and these were expressed as the fold-change relative to $\beta$-actin (25).

Western blot analysis. Briefly, HUGECs were successfully transfected with LXR- $\alpha$ shRNA and treated with $2 \mu \mathrm{M}$ T0901317 for $24 \mathrm{~h}$. Cells were then exposed to $25 \mathrm{mM}$ glucose or $25 \mathrm{mM}$ mannitol for $6 \mathrm{~h}$ to induce high-glucose conditions. Cells were collected and lysed in $2 \mathrm{X}$ lysis buffer (200 $\mu 1 / 50 \mathrm{~cm}^{2}$; Beyotime Institute of Biotechnology). Samples were resolved by sodium dodecyl sulphate-polyacrylamide gel electrophoresis (SDS-PAGE; 10\% gels; run at 100 Volts for $1 \mathrm{~h}$ ) and electroblotted onto a polyvinylidene difluoride membrane. The membranes were then blocked with $5 \%$ bovine serum albumin (BSA; Hyclone; GE Healthcare Life Sciences, Logan, UT, USA) in Tris-buffered saline and Tween 20 buffer, and incubated with mouse monoclonal TM (1:500),

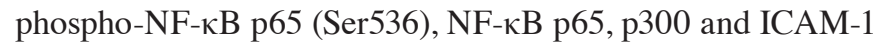
$(1: 1,000)$, goat polyclonal LXR- $\alpha$ and mouse monoclonal LXR- $\beta$ (1:200), and rabbit monoclonal ІкB $\alpha$, phospho-ІкB $\alpha$ (Ser32) and $\beta$-actin $(1: 1,000)$ primary antibodies overnight at $4^{\circ} \mathrm{C}$. Membranes were then incubated with horseradish peroxidase-conjugated mouse anti-rabbit, goat anti-mouse or rabbit anti-goat IgGs (1:5,000; Santa Cruz Biotechnology, Inc., Dallas, TX, USA; cat. nos. sc-2357, sc-2005 and sc-2299, respectively) for $1 \mathrm{~h}$ at room temperature. Primary antibodies against TM, LXR- $\alpha$, LXR- $\beta$, p300 and ICAM- 1 were purchased from Santa Cruz Biotechnology (cat. nos. sc-271804, sc-133221, sc-1202, sc-8439 and sc-48343, respectively).

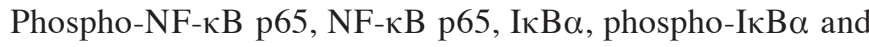
$\beta$-actin were purchased from Cell Signaling Technology, Inc. (Danvers, MA, USA; cat. nos. 6956, 13346, 2859, 4812 and 8457 , respectively). The proteins were detected using the SignalFire ECL Reagent (Cell Signaling Technology, Inc.; cat. no. 6883). Protein expression was quantified by densitometry using the Quantity One 1-D analysis software, version 4.6.2 (Bio-Rad Laboratories, Inc.).

Immunoprecipitation and immunoblotting. HUGECs were treated with media containing $200 \mu \mathrm{M} \mathrm{CaCl}_{2}$ and dimethylsulfoxide or $2 \mu \mathrm{M}$ T0901317. The media covering the cells was removed after $24 \mathrm{~h}$, and the cells were washed once with phosphate-buffered saline containing $\mathrm{CaCl}_{2}$. The cells were then scraped from the plates in $200 \mu$ lice-cold lysis buffer containing $25 \mathrm{mM}$ Tris (pH 8.0), $150 \mathrm{mM} \mathrm{NaCl}, 2$ mM EDTA, $1 \%$ Triton X-100, and protease and phosphatase inhibitors (Nacalai USA, Inc., San Diego, CA, USA). The lysed cells were pipetted into $1.5 \mathrm{ml}$ tubes (Eppendorf, Hamburg, Germany), incubated on ice for $30 \mathrm{~min}$ and microcentrifuged at $14,000 \mathrm{x} \mathrm{g}$ for $30 \mathrm{~min}$ at $4^{\circ} \mathrm{C}$. Clarified lysates were incubated overnight at $4^{\circ} \mathrm{C}$ with $0.2 \mu \mathrm{g} \mathrm{p} 300$ (sc-48343) or LXR- $\alpha$ (sc-1202p) monoclonal antibody, and subsequently were incubated for $1 \mathrm{~h}$ with Protein A/G agarose (Life Technologies; Thermo Fisher Scientific). The beads were extensively washed in lysis buffer 3 times for $5 \mathrm{~min}$, and bound proteins were eluted in SDS sample buffer prior to western blot analysis.

Enzyme-linked immunosorbent assay (ELISA) for proinflammatory cytokines. Diabetes mellitus is characterized by a systemic proinflammatory environment, exhibiting enhanced basal and postprandial circulating levels of proinflammatory cytokines, including IL-1 $\beta$, IL- 6 and TNF- $\alpha$ (11). To examine the quantity of IL- $1 \beta$, and TNF- $\alpha$ in the supernatant of HUGECs, commercially available ELISA kits were used. IL- $1 \beta$ and TNF- $\alpha$ ELISA kits (EH2IL1B, EH3TNFA) were obtained from Thermo Fisher Scientific, Inc. In accordance with the manufacturer's protocol, all supernatants were stored at $-80^{\circ} \mathrm{C}$ prior to assessment. The supernatants and standards were centrifuged at $1200 \mathrm{x} \mathrm{g}$ for 3 min at $4^{\circ} \mathrm{C}$ and run in triplicates. Optical density (OD) at $450 \mathrm{~nm}$ was calculated by subtracting the background, and standard curves were plotted.

Protein $C(P C)$ activation assay. The first group of HUGECs were treated with $2 \mu \mathrm{M}$ T0901317 for $0,6,12$ or $24 \mathrm{~h}$; the other two groups of cells were transfected with pHBAd-U6-GFP-shRNA/TM (AdTMshRNA) or AdControl first, and subsequently $2 \mu \mathrm{M}$ T0901317 was administered to the first group. TM activity was assessed by determining PC activation in early confluent cells cultured in 96-well plates. The cells were rinsed with buffer containing $20 \mathrm{mM}$ Tris (pH 7.4), $0.15 \mathrm{M} \mathrm{NaCl}, 2.5 \mathrm{mM} \mathrm{CaCl}_{2}$ and $5 \mathrm{mg} / \mathrm{ml} \mathrm{BSA}$ and then incubated with $40 \mu \mathrm{l}$ reaction mixture $(37.5 \mathrm{nM}$ thrombin and $5 \mu \mathrm{g} / \mathrm{ml} \mathrm{PC}$ in the washing buffer) at $37^{\circ} \mathrm{C}$ for $30 \mathrm{~min}$. PC activity was terminated by adding $40 \mu 1$ argatroban $(0.5 \mathrm{mg} / \mathrm{ml})$ and heparin (24 International Units $/ \mathrm{ml})$. The quantity of activated PC (APC) was determined by monitoring the hydrolysis of chromogenic substrate at $405 \mathrm{~nm}$ in a Tecan Sunrise microtiter plate reader (Tecan Australia Pty Ltd., Melbourne, Australia). The results are expressed as the mean OD slope values $(\Delta \mathrm{OD} / \Delta \mathrm{t})$. The human PC and human thrombin, and chromogenic substrate for APC were obtained from Merck Millipore (cat. no. 605190-100U, cat. no. 539215-50UG; Darmstadt, Germany).

Statistical analysis. Results from at least three independent experiments were analyzed with one-way analysis of variance using SPSS software, version 18 (SPSS, Inc., Chicago, IL, USA). All data are expressed as the mean \pm standard deviation. $\mathrm{P}<0.05$ was considered to indicate a statistically significant difference.

\section{Results}

LXRs are constitutively expressed in HUGECs, and LXR agonist T0901317 further enhances their function. To investigate the expression and function of LXRs in HUGECs, HUGECs were treated with LXR agonist T0901317 (2 or $4 \mu \mathrm{M})$ 
for $24 \mathrm{~h}$, and the expression of LXR- $\alpha$ and LXR- $\beta$ was subsequently examined. Western blot analysis indicated that LXR- $\alpha$ and LXR- $\beta$ were constitutively expressed in HUGECs (Fig. 1A and B). Addition of the LXR agonist, T0901317, did not result in an upregulation of the expression of LXR- $\alpha$ or LXR- $\beta$ following $48 \mathrm{~h}$ of treatment (data not shown). Following confirmation of LXR expression, the functionality of LXR in HUGECs was investigated by detecting the transcription level of ABCA1, one of the LXR target genes $(26,27)$. RT-qPCR indicated that treatment with T0901317 significantly increased the mRNA expression level of ABCA1 in HUGECs in a dose-dependent manner ( $\mathrm{P}<0.05$; Fig. 1C).

LXR agonist T0901317 upregulates the expression of TM in HUGECs. As it was determined that LXR is functional in HUGECs, it was then investigated whether the activation of LXR may be involved in the regulation of TM. RT-qPCR analysis indicated that treatment of HUGECs with T0901317 led to significantly increased mRNA expression levels of TM in a dose-dependent manner $(\mathrm{P}<0.05$; Fig. 2A). A similar dose-dependent increase in protein expression levels was confirmed by western blot analysis $(\mathrm{P}<0.05$; Fig. $2 \mathrm{~B})$. Notably, RT-qPCR indicated that only LXR- $\alpha$-siRNA, and not LXR- $\beta$-siRNA or scrambled siRNA, significantly inhibited T0901317-induced expression of TM in HUGECs $(\mathrm{P}<0.05$; Fig. 2C). These results for the protein expression levels were confirmed by western blot analysis $(\mathrm{P}<0.05$; Fig. 2D). The present data suggest that activation of LXR by the agonist, T0901317, induces upregulation of TM in HUGECs, more specifically through LXR- $\alpha$.

Upregulation of TM expression by LXR is dependent on $N F-\kappa B$ inhibition. As LXR is a classical transcriptional factor, it was hypothesized that LXR upregulates TM expression via directly enhancing the activity of the TM promoter. To assess this, luciferase reporter plasmids were constructed, driven by the human TM promoter. A reporter assay indicated that T0901317 did not increase the activity of the TM promoter $(-2494$ to $+160 \mathrm{bp})$ when transfected with various luciferase reporter plasmids (data not shown). It is possible that LXR upregulates TM expression via indirectly modulating the activity of other transcription factors. To determine the role of NF- $\kappa \mathrm{B}$ in mediating the LXR- $\alpha$-induced upregulation of TM, the effect of LXR activation on the NF- $\kappa B$ pathway in HUGECs was investigated by western blot analysis. High-glucose conditions induced the phosphorylation of $\mathrm{I} \kappa \mathrm{B} \alpha$ and the translocation of NF- $\mathrm{NB}$ p 65 to the nucleus in HUGECs, compared with the osmotic control (Fig. 3A). However, the LXR agonist T0901317 suppressed the phosphorylation of I $\kappa \mathrm{B} \alpha$ (Fig. 3A) and inhibited the nuclear translocation of $\mathrm{NF}-\kappa \mathrm{B}$ p65 under high-glucose conditions (Fig. 3B). The activity of NF- $\kappa B$ was further increased by LXR- $\alpha$ silencing, despite the presence of T0901317 (Fig. 3C and D). These data highlight the possible involvement of LXR regulation of $\mathrm{NF}-\kappa \mathrm{B}$ activation in TM induction.

Modulation of TM expression by interaction of p300 with $L X R$ - $\alpha$. Subsequently, in vitro experiments were performed to gain further insights into the mechanism through which the LXR agonist upregulates the expression of TM via the
A

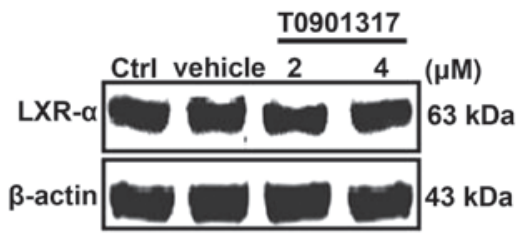

B

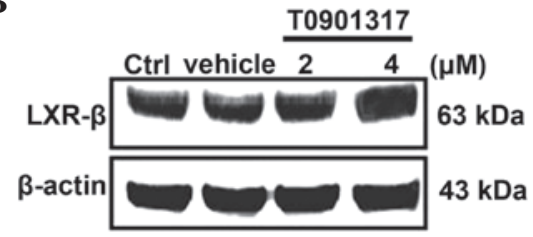

C

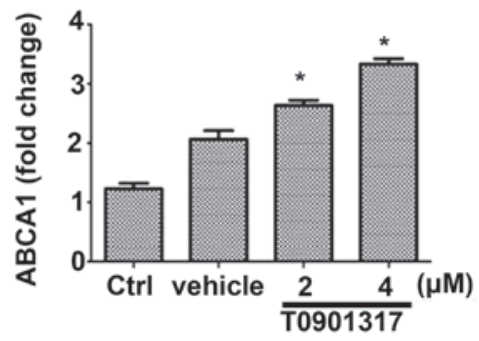

Figure 1. LXRs are expressed and functional in HUGECs. HUGECs were treated with 2 or $4 \mu \mathrm{M}$ LXR agonist T0901317 for $24 \mathrm{~h}$. (A) Expression of LXR- $\alpha$ and (B) LXR- $\beta$ in HUGECs was assessed by western blotting. Data shown are representative of one of three independent experiments. (C) ABCA1 expression increases in a dose-dependent manner in HUGECs. Data are presented as the mean \pm standard deviation, and are representative of three independent experiments performed in triplicate $\left({ }^{*} \mathrm{P}<0.05\right)$. LXR $-\alpha,-\beta$, liver $\mathrm{X}$ receptor- $\alpha,-\beta$; ABCA1, ATP-binding cassette transporter A1; Ctrl, control; HUGECs, human glomerular endothelial cells.

NF- $\kappa$ B/p300 pathway. The effect of T0901317 stimulation on the interaction of p300 with the LXR- $\alpha$ was also investigated. Therefore, co-immunoprecipitation experiments were performed on extracts from HUGECs with or without T0901317 stimulation for $24 \mathrm{~h}$. An interaction between p300 and LXR- $\alpha$ was demonstrated on the basis of the co-immunoprecipitation experiment, and the treatment of cells with $2 \mu \mathrm{M}$ T0901317 enhanced this interaction (Fig. 4).

pHBAd-U6-GFP-siRNA/TM inhibits the expression of TM in HUGECs. The evidence of endonuclease digestion and sequencing indicated that the recombinant adenovirus vector, pHBAd-U6-GFP-siRNA/TM, hadbeensuccessfullyconstructed. The expression of GFP was observed in HEK293 cells infected with pHBAd-U6-GFP-siRNA/TM (data not shown). In the present study, it was observed that transfection with the recombinant adenovirus vector, pHBAd-U6-GFP-siRNA/TM, significantly reduced the protein expression levels of TM $(\mathrm{P}<0.05$; Fig. 5).

LXR agonist T0901317 inhibits the secretion of inflammatory cytokines and increases APC activity in HUGECs. As TM has anti-inflammatory effects on PC, the secretion of inflammatory cytokines in HUGECs was examined upon hyperglycemia. The cells were transfected with pHBAd-U6-GFP-shRNA/TM prior to hyperglycemia stimulation. As presented in Fig. 6A and B, high-glucose conditions (25 mM glucose) significantly increased the level of IL- $1 \beta$ and TNF- $\alpha$ in HUGECs, compared 
A

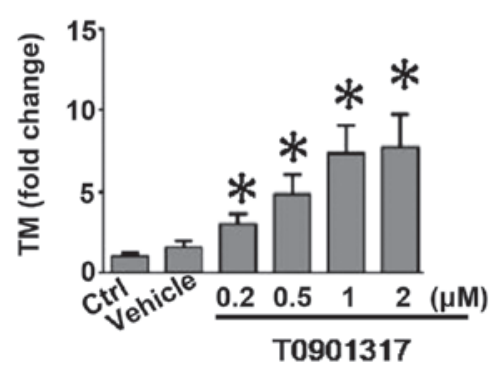

C

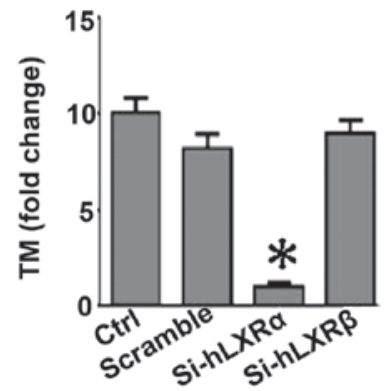

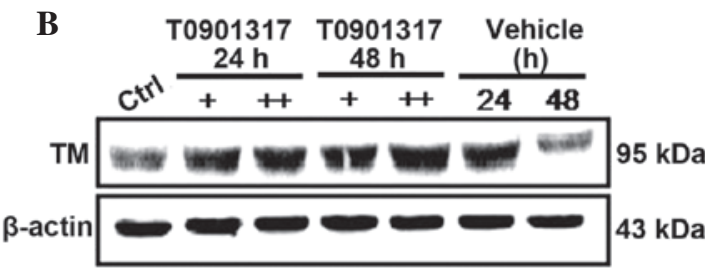

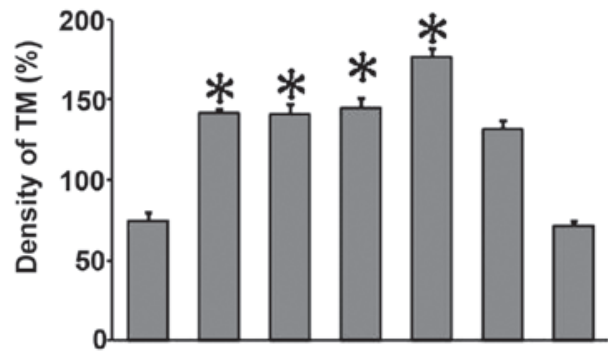

D

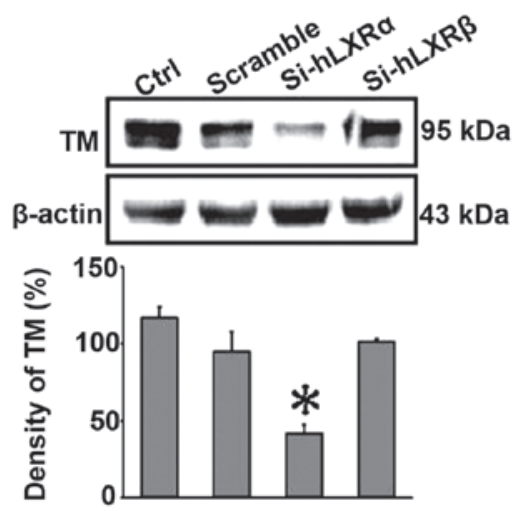

Figure 2. LXR agonist T0901317 upregulates TM expression in HUGECs. (A) HUGECs were treated with T0901317 (0.2, $0.5,1$ or $2 \mu$ M) for 24 h. LXR agonist upregulated the level of TM in a dose-dependent manner. (B) HUGECs were treated with 2 or $4 \mu \mathrm{M}$ T0901317 for either a 24 or a $48 \mathrm{~h}$ time period. LXR agonist upregulated the level of TM in a dose-dependent manner, as determined by western blotting. (C) HUGECs were transfected with Si-hLXR $\alpha$ or Si-hLXR $\beta$, and the fold change in TM was monitored. (D) HUGECs were transfected with Si-hLXR $\alpha$ or Si-hLXR $\beta$. The protein expression of TM in HUGECs was measured by western blot analysis. Data are presented as the mean \pm standard deviation ( $\left.{ }^{*} \mathrm{P}<0.05\right)$. +, $1 \mu \mathrm{M}$ T0901317; ++, $2 \mu \mathrm{M}$ T0901317; Ctrl, control; HUGECs, human glomerular endothelial cells; TM, thrombomodulin; LXR- $\alpha,-\beta$, liver X receptor- $\alpha,-\beta$; siRNA, small interfering RNA; Si-hLXR $\alpha$, LXR $\alpha$-siRNA; Si-hLXR $\beta$, LXR $\beta$-siRNA.

with the $25 \mathrm{mM}$ glucose treatment $(\mathrm{P}<0.05)$. The LXR agonist T0901317 $(2 \mu \mathrm{M})$ prevented glucose-induced inflammatory cytokine secretion. The levels of TNF- $\alpha$ (Fig. 6A) and IL-1 $\beta$ (Fig. 6B) were increased by TM silencing, despite the presence of T0901317. The production of APC was markedly increased in HUGECs following treatment with $2 \mu \mathrm{M}$ T0901317 for $12 \mathrm{~h}$; however, the production of APC was reduced by TM silencing, despite the presence of T0901317 (Fig. 6C), indicating that LXR activation may induce TM activity in HUGECs. An increased expression of ICAM-1 following high-glucose stimulation was not detected (data not shown). The present findings suggest that LXR agonists may inhibit the inflammatory response of HUGECs via TM activation.

\section{Discussion}

As a key component of the PC anticoagulant pathway, TM expressed by endothelial cells is an important anti-inflammatory factor. The present study indicated that LXR- $\alpha$ and LXR- $\beta$ were expressed in HUGECs. Additionally, the LXR agonist, T0901317, promoted transcription of ABCA1 in HUGECs, which was identified as one of the LXR targets and upregulated by LXR activation (28-30). In the present study, the LXR agonist T0901317 significantly increased the expression of TM in HUGECs. Previous studies suggest that LXR activation may enhance TM activity via the TM-thrombin-PC system. Activated TM simultaneously binds to thrombin and PC to form a complex on the surface of endothelial cells, which expresses the endothelial cell PC receptor (EPCR) (31-33). APC binds with EPCR to downregulate the production of inflammatory cytokines (34). The current study identified that the LXR agonist T0901317 inhibited the secretion of inflammatory cytokines, and increased the TM activity in HUGECs. Due to the close association between APC and TM activity, the present results indicate that the LXR/TM pathway may be a novel mechanism for LXR-mediated protection of the cells against inflammation.

Previous studies have determined that $\mathrm{NF}-\kappa \mathrm{B}$ may regulate the activities of certain transcription factors by competitively binding with the p300/CBP complex within the nucleus $(35,36)$. As previous studies have reported, $\mathrm{NF}-\kappa \mathrm{B}$ may be the target gene for the promoter region of $\operatorname{LXR}(14,15)$. The present study determined that inhibition of $\mathrm{NF}-\kappa \mathrm{B}$ may be a critical requirement for the LXR agonist upregulating the expression of TM in vitro. T0901317 suppressed the phosphorylation of I $\mathrm{B} \alpha$ and inhibited the nuclear translocation of $N F-\kappa B$ p 65 protein 
A

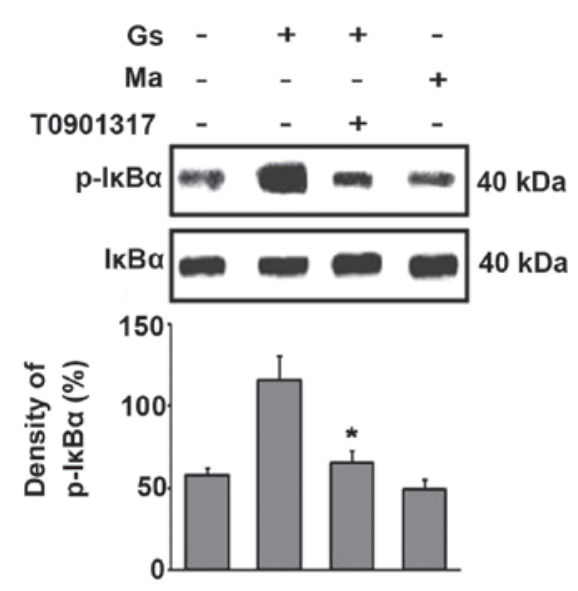

C

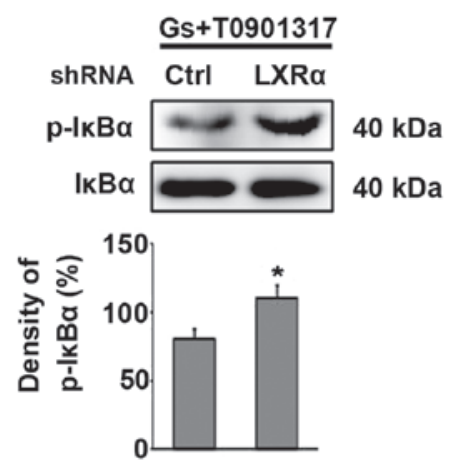

B

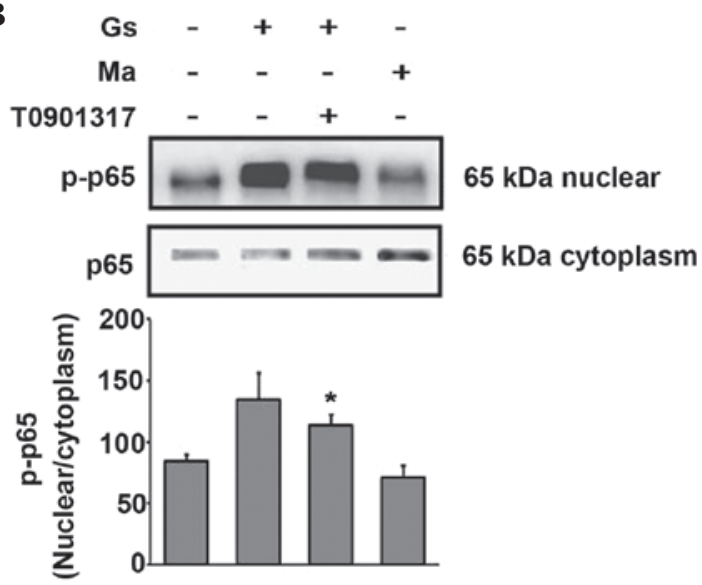

D

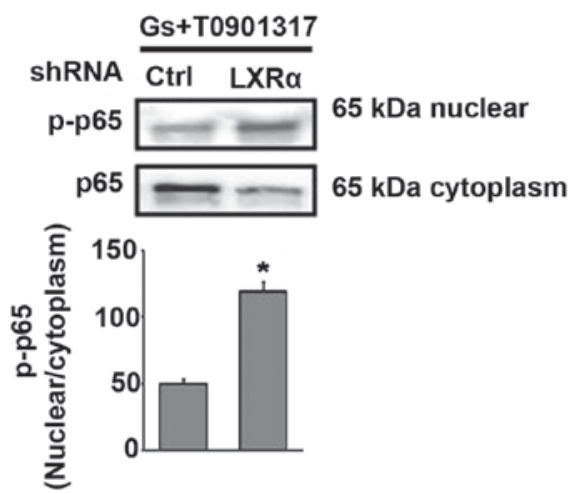

Figure 3. Upregulation of TM expression by LXR is dependent on NF- $\kappa$ B inhibition. The HUGECs were treated with $2 \mu \mathrm{M}$ T0901317 for $24 \mathrm{~h}$. These cells were then exposed to $25 \mathrm{mM}$ glucose or $25 \mathrm{mM}$ mannitol for $6 \mathrm{~h}$. Prior to T0901317 treatment, HUGECs were successfully transfected with LXR- $\alpha$

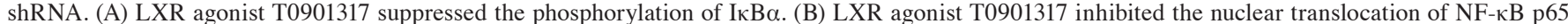
in high-glucose conditions. (C) The expression of p-IкB $\alpha$ upon LXR- $\alpha$ silencing, despite the presence of T0901317,as assessed by western blotting. (D) The expression of p-p65 upon LXR- $\alpha$ silencing, despite the presence of T0901317, as determined by western blotting. Data are expressed as the mean \pm standard deviation ( $\mathrm{P}<0.05)$. Gs, glucose treatment; HUGECs, human glomerular endothelial cells; LXR, liver X receptor; Ma, mannitol treatment; NF- $\kappa B$, nuclear factor- $\kappa \mathrm{B}$; p-I $\mathrm{B} \alpha$, phospho-nuclear factor of $\kappa$ light polypeptide gene enhancer in B-cells inhibitor; shRNA, small hairpin RNA; TM, thrombomodulin.

following high-glucose treatment. This result is consistent with a previous study, in which an LXR agonist inhibited I $\kappa \mathrm{B}$ phosphorylation and $\mathrm{NF}-\kappa \mathrm{B}$ p 65 translocation into the nucleus, which resulted in an increase in the protein expression of heme oxygenase-1 (37). The current findings suggest that the inhibition of TM by NF- $\mathrm{TB}$ was possibly achieved indirectly by competition for the coactivator, p300/CBP, whereas $\mathrm{NF}-\kappa \mathrm{B}$ predominantly acts as a transcriptional activator (38). The mechanism by which $\mathrm{NF}-\kappa \mathrm{B}$ may regulate gene expression is through competition for other transcription factors. The transcriptional coactivator, p300, functions almost identically with histone acetyltransferase, which modulates the activities of $\mathrm{NF}-\kappa \mathrm{B}$ transcription factors (36). The current study determined that treatment of the cells with T0901317 enhanced the interaction between LXR- $\alpha$ and p300, compared with the vehicle control group. A previous study reported that TM and p300 are capable of forming a complex, and LXR may compete with p300 to form a complex with TM (39). The co-immunoprecipitation results of the current study suggested that the inhibition of $\mathrm{TM}$ expression by $\mathrm{NF}-\kappa \mathrm{B}$ may be indirectly achieved through competition with the coactivator, p300/CBP. Competition with p300/CBP may also provide an explanation for the observation that all-trans-retinoic acid
(ATRA) is hypothesized to stimulate the basal gene expression of TM, thus preventing the downregulation of TM in response to TNF- $\alpha(40,41)$. It is possible that ATRA or cAMP-induced phosphorylation of the transcription factor $\mathrm{Sp} 1$ increases the affinity of p300/CBP for the Sp1-Ets nucleosome, thereby preventing it from associating with $\mathrm{NF}-\kappa \mathrm{B}$. The mechanism by which LXRs regulate TM expression has yet to be fully elucidated. Therefore, further investigation should be conducted to elucidate the mechanism of LXR in modulating TM expression.

It is generally accepted that endothelial dysfunction is important for the development of diabetic microvascular disease (42). Microvascular disease may lead to organ damage through impaired vascular function, increased inflammation or apoptosis $(43,44)$. Microvascular complications in DN have been associated with the hyperglycemia-induced inflammatory response in mice and humans (45-47). In unperturbed endothelial cells, activation of PC that is dependent on TM inhibits coagulation, inflammation and apoptosis (48). The function of the endothelial TM-PC system is impaired in diabetic individuals. This is indicated by the increased levels of soluble TM, which reflects a loss of TM from the endothelium and reduced levels of APC $(49,50)$. 


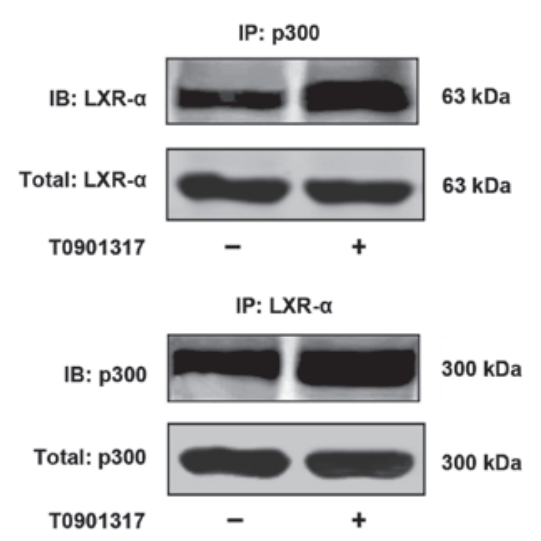

Figure 4. Modulation of thrombomodulin expression by $\mathrm{p} 300$. HUGECs were treated with $2 \mu \mathrm{M}$ T0901317 for $24 \mathrm{~h}$. When the HUGECs were treated with $2 \mu \mathrm{M}$ T0901317, there was an enhanced interaction between $\mathrm{p} 300$ and LXR- $\alpha$, as assessed by co-immunoprecipitation. HUGECs, human glomerular endothelial cells; IB, immunoblot; LXR- $\alpha$, liver X receptor- $\alpha$; p300, transcriptional coactivator.

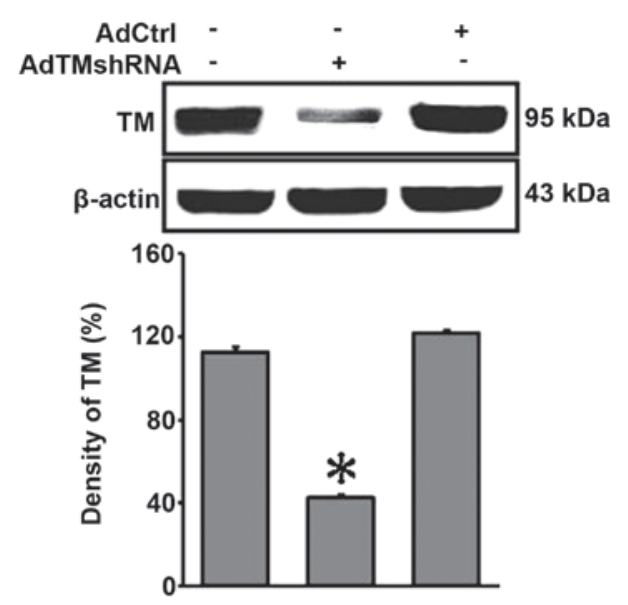

Figure 5. pHBAd-U6-GFP-siRNA/TM inhibits the expression of TM in HUGECs. HUGECs were transfected with the recombinant adenovirus vector, pHBAd-U6-GFP-siRNA/TM, which consequently led to a significant reduction in the expression of TM, as indicated by the western blot. Data are presented as the mean \pm standard deviation $\left({ }^{*} \mathrm{P}<0.05\right)$. AdCtrl, adenovirus control; ADTMshRNA, the recombinant adenovirus vector; HUGECs, human glomerular endothelial cells; TM, thrombomodulin.

The ability to keep the endothelial balance by exogenous administration of soluble TM via downregulation of specific adhesion molecules and chemokines suggests a potential therapeutic target for intervention in kidney disease associated with chronic inflammation (51). Thus, upregulation of TM in GECs may provide a potential intervention to ameliorate inflammatory endothelial cell dysfunction in diabetes. The synthesis of active TM in endothelial cells and mesangial cells within the glomerulus stresses its importance in maintaining renal hemostatic equilibrium (52). In the current study, activation of LXR induced the activation of TM, and reduced the secretion of proinflammatory mediators in hyperglycemia-stimulated HUGECs. Following transfection with the recombinant adenovirus vector and TM silencing in the HUGECs, the secretion of proinflammatory cytokines was upregulated, and PC activation was reduced compared with the normal control, even subsequently to the administration of

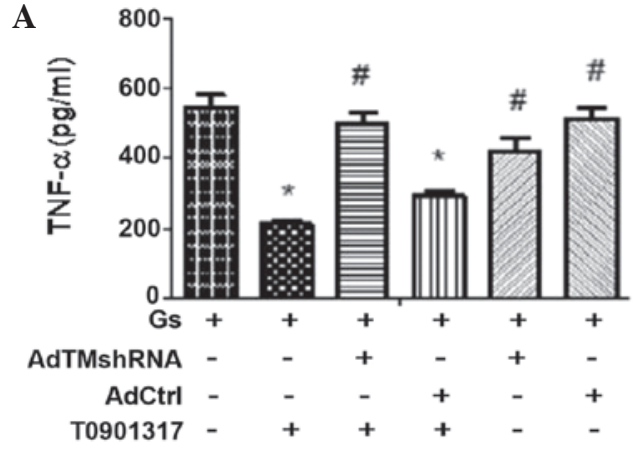

B

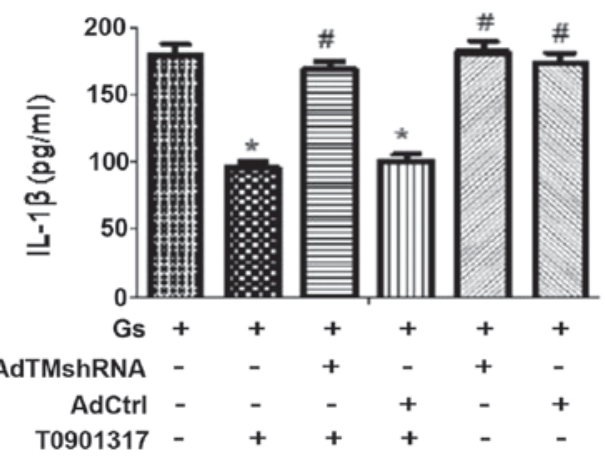

C

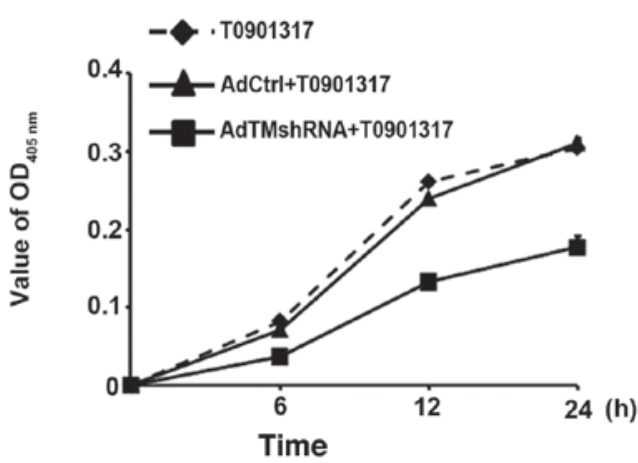

Figure 6. LXR agonist T0901317 inhibits the secretion of inflammatory cytokines, and improves APC activity in HUGECs. HUGECs were treated with $2 \mu \mathrm{M}$ T0901317 for $24 \mathrm{~h}$. Subsequently, these cells were exposed to $25 \mathrm{mM}$ glucose for $6 \mathrm{~h}$. Prior to T0901317 treatment, the cells were successfully transfected with the recombinant adenovirus vector, pHBAd-U6-GFP-siRNA/TM. Levels of (A) TNF- $\alpha$ and (B) IL-1 $\beta$ were increased by TM silencing, despite the presence of T0901317. (C) Production of APC was reduced by TM silencing, despite the presence of T0901317. Data are presented as mean \pm standard deviation $\left(" \mathrm{P}<0.05\right.$; $\left.{ }^{*} \mathrm{P}<0.01\right)$. AdCtrl, adenovirus control; APC, activated protein C; TNF- $\alpha$, tumor necrosis factor- $\alpha$; HUGECs, human glomerular endothelial cells; Gs, glucose treatment; IL1-1 $\beta$, interleukin-1 $\beta$; OD, optical density; TM, thrombomodulin.

LXR agonists. Thus, TM-dependent APC formation and the reduction of proinflammatory mediator secretion may prevent endothelial dysfunction, glomerular capillary injury and DN. The induction of adhesion molecules on activated endothelial cells is crucial in monocyte recruitment during the atherogenic process in DN (53). The current findings did not determine whether high-glucose treatment increases the expression of ICAM-1. This indicated that the elevation of extracellular D-glucose levels may be insufficient to induce vascular inflammation. A previous study has indicated that sera from patients with diabetes contains components, which are capable of inducing vascular cell adhesion molecule-1 expression in 
endothelial cells independently of hyperglycemia (53). Further investigation is required to elucidate the effect of LXR ligands on TM expression in diabetic nephropathy.

LXR- $\beta$ is expressed ubiquitously, whereas LXR- $\alpha$ is expressed at high levels in cholesterol-metabolizing tissues (54). In the current study, the two isoforms of LXR, i.e., LXR- $\alpha$ and LXR- $\beta$, were expressed constitutively in HUGECs. Transfection of LXR- $\alpha$-siRNA was sufficient to suppress TM expression; however, LXR- $\beta$ did not perform an identical function in HUGECs following LXR- $\beta$-siRNA transfection. Additionally, the activity of the $N F-\kappa B$ pathway was upregulated by LXR- $\alpha$ silencing, despite the presence of T0901317, indicating LXR- $\alpha$ may be important in modulating TM expression in HUGECs. T0901317 is a dual agonist that activates LXR- $\alpha$ and LXR- $\beta$ (55); however, the function of endogenous LXR- $\beta$, which is involved in the regulation of TM expression, should not be excluded. On the basis of the similarity of locations in endothelial cells and anti-inflammatory functions between LXR and TM, LXR may be a potential 'positive mediator' in regulating the expression of TM.

In conclusion, the present study, to the best of our knowledge is the first to report that LXR activation may upregulate TM expression in HUGECs. It also identified that $\mathrm{NF}-\kappa \mathrm{B}$ inhibition may be a critical mediator of TM activation in vitro, providing a novel therapeutic target for the treatment of inflammatory diseases characterized by a low expression of TM.

\section{Acknowledgements}

The current study was supported by a grant from the National Natural Science Foundation of China (grant no. 81170680, awarded to Hanlu Ding) and the Science \& Technology Department of Sichuan Province (grant no. 2013JY0141).

\section{References}

1. Goldberg RB: Cytokine and cytokine-like inflammation markers, endothelial dysfunction, and imbalanced coagulation in development of diabetes and its complications. J Clin Endocrinol Metab 94: 3171-3182, 2009.

2. Conway EM: Thrombomodulin and its role in inflammation. Semin Immunopathol 34: 107-125, 2012.

3. Mangan S, Clancy P and Golledge J: Modulation of endothelial cell thrombomodulin by PPAR ligands - variation according to environment. Thromb Res 121: 827-834, 2008.

4. Kondo K, Ishida T, Yasuda T, Nakajima H, Mori K, Tanaka N, Mori T, Monguchi T, Shinohara M, Irino Y, et al: Trans-fatty acid promotes thrombus formation in mice by aggravating antithrombogenic endothelial functions via Toll-like receptors. Mol Nutr Food Res 59: 729-740, 2015.

5. He X, Xu Z, Wang B, Zheng Y, Gong W, Huang G, Zhang L, Li Y, He F: Upregulation of thrombomodulin expression by activation of farnesoid $\mathrm{X}$ receptor in vascular endothelial cells. Eur J Pharmacol 718: 283-289, 2013.

6. Szanto A and Roszer T: Nuclear receptors in macrophages: A link between metabolism and inflammation. FEBS Lett 582: 106-116, 2008.

7. Calkin AC and Tontonoz P: Liver x receptor signaling pathways and atherosclerosis. Arterioscler Thromb Vasc Biol 30: 1513-1518, 2010.

8. Joseph SB, Castrillo A, Laffitte BA, Mangelsdorf DJ and Tontonoz P: Reciprocal regulation of inflammation and lipid metabolism by liver X receptors. Nat Med 9: 213-219, 2003.

9. Peet DJ, Turley SD, Ma W, Janowski BA, Lobaccaro JM, Hammer RE and Mangelsdorf DJ: Cholesterol and bile acid metabolism are impaired in mice lacking the nuclear oxysterol receptor LXR alpha. Cell 93: 693-704, 1998.
10. Fowler AJ, Sheu MY, Schmuth M, Kao J, Fluhr JW, Rhein L Collins JL, Willson TM, Mangelsdorf DJ, Elias PM and Feingold KR: Liver X receptor activators display anti-inflammatory activity in irritant and allergic contact dermatitis models: liver-X-receptor-specific inhibition of inflammation and primary cytokine production. J Invest Dermatol 120: 246-255, 2003.

11. Joseph SB, Bradley MN, Castrillo A, Bruhn KW, Mak PA, Pei L, Hogenesch J, O'connell RM, Cheng G, Saez E, et al: LXR-dependent gene expression is important for macrophage survival and the innate immune response. Cell 119: 299-309, 2004.

12. Valledor AF, Hsu LC, Ogawa S, Sawka-Verhelle D, Karin M and Glass CK: Activation of liver X receptors and retinoid X receptors prevents bacterial-induced macrophage apoptosis. Proc Natl Acad Sci USA 101: 17813-17818, 2004.

13. Baranowski M: Biological role of liver X receptors. J Physiol Pharmacol 59 (Suppl 7): 31-55, 2008.

14. Yang SM, Ka SM, Wu HL, Yeh YC, Kuo CH, Hua KF, Shi GY, Hung YJ, Hsiao FC, Yang SS, et al: Thrombomodulin domain 1 ameliorates diabetic nephropathy in mice via anti-NF- $\kappa$ B/NLRP3 inflammasome-mediated inflammation, enhancement of NRF2 antioxidant activity and inhibition of apoptosis. Diabetologia 57: 424-434, 2014.

15. Wang H, Vinnikov I, Shahzad K, Bock F, Ranjan S, Wolter J, Kashif M, Oh J, Bierhaus A, Nawroth P, et al: The lectin-like domain of thrombomodulin ameliorates diabetic glomerulopathy via complement inhibition. Thromb Haemost 108: 1141-1153, 2012.

16. Jayaraman G, Srinivas R, Duggan C, Ferreira E, Swaminathan S, Somasundaram K, Williams J, Hauser C, Kurkinen M, Dhar R, et al: p300/cAMP-responsive element-binding protein interactions with ets- 1 and ets- 2 in the transcriptional activation of the human stromelysin promoter. J Biol Chem 274: 17342-17352, 1999.

17. Sheppard KA, Rose DW, Haque ZK, Kurokawa R, McInerney E, Westin S, Thanos D, Rosenfeld MG, Glass CK and Collins T: Transcriptional activation by NF-kappaB requires multiple coactivators. Mol Cell Biol 19: 6367-6378, 1999.

18. Birrell MA, Catley MC, Hardaker E, Wong S, Willson TM, McCluskie K, Leonard T, Farrow SN, Collins JL, Haj-Yahia S and Belvisi MG: Novel role for the liver X nuclear receptor in the suppression of lung inflammatory responses. J Biol Chem 282: 31882-31890, 2007.

19. Mogilenko DA, Kudriavtsev IV, Trulioff AS, Shavva VS, Dizhe EB, Missyul BV, Zhakhov AV, Ischenko AM, Perevozchikov AP and Orlov SV: Modified low density lipoprotein stimulates complement $\mathrm{C} 3$ expression and secretion via liver $\mathrm{X}$ receptor and Toll-like receptor 4 activation in human macrophages. J Biol Chem 287: 5954-5968, 2012.

20. Cheng O, Ostrowski RP, Liu W and Zhang JH: Activation of liver X receptor reduces global ischemic brain injury by reduction of nuclear factor-kappaB. Neuroscience 166: 1101-1109, 2010.

21. Chen S, Sorrentino R, Shimada K, Bulut Y, Doherty TM, Crother TR and Arditi M: Chlamydia pneumoniae-induced foam cell formation requires MyD88-dependent and-independent signaling and is reciprocally modulated by liver $\mathrm{X}$ receptor activation. J Immunol 181: 7186-7193, 2008.

22. Puddu GM, Cravero E, Arnone G, Muscari A and Puddu P: Molecular aspects of atherogenesis: New insights and unsolved questions. J Biomed Sci 12: 839-853, 2005.

23. Wang GX, Hu L, Zhang Z and Liu DP: Construction of an adenoviral expression vector carrying FLAG and hrGFP-1 genes and its expression in bone marrow mesenchymal stem cells. Genet Mol Res 13: 1070-1078, 2014.

24. Luo J, Deng ZL, Luo X, Tang N, Song WX, Chen J, Sharff KA, Luu $\mathrm{HH}$, Haydon RC, Kinzler KW, et al: A protocol for rapid generation of recombinant adenoviruses using the AdEasy system. Nature Protoc 2: 1236-1247, 2007.

25. Edmunds RC, McIntyre JK, Luckenbach JA, Baldwin DH and Incardona P: Toward enhanced MIQE compliance: Reference residual normalization of $\mathrm{qPCR}$ gene expression data. J Biomol Tech 25: 54-60, 2014.

26. Khovidhunkit W, Moser AH, Shigenaga JK, Grunfeld C and Feingold KR: Endotoxin down-regulates ABCG5 and ABCG8 in mouse liver and ABCA1 and ABCG1 in J774 murine macrophages: Differential role of LXR. J Lipid Res 44: 1728-1736, 2003.

27. Stefulj J, Panzenboeck U, Becker T, Hirschmugl B, Schweinzer C, Lang I, Marsche G, Sadjak A, Lang U, Desoye G and Wadsack C: Human endothelial cells of the placental barrier efficiently deliver cholesterol to the fetal circulation via ABCA1 and ABCG1. Circ Res 104: 600-608, 2009. 
28. Ishibashi M, Filomenko R, Rébé C, Chevriaux A, Varin A, Derangère $V$, Bessède $G$, Gambert $P$, Lagrost $L$ and Masson $D$ : Knock-down of the oxysterol receptor LXRalpha impairs cholesterol efflux in human primary macrophages: Lack of compensation by LXR $\beta$ activation. Biochem Pharmacol 86 : 122-129, 2013

29. Repa JJ, Turley SD, Lobaccaro JA, Medina J, Li L, Lustig K, Shan B, Heyman RA, Dietschy JM and Mangelsdorf DJ: Regulation of absorption and ABC1-mediated efflux of cholesterol by RXR heterodimers. Science 289: 1524-1529, 2000.

30. Wang N, Lan D, Chen W, Matsuura F and Tall AR: ATP-binding cassette transporters G1 and G4 mediate cellular cholesterol efflux to high-density lipoproteins. Proc Natl Acad Sci USA 101: 9774-9779, 2004.

31. Feistritzer $\mathrm{C}$ and Riewald M: Endothelial barrier protection by activated protein $\mathrm{C}$ through PAR1-dependent sphingosine 1-phosphate receptor-1 crossactivation. Blood 105 3178-3184, 2005.

32. Matsumoto H, Yamakawa K, Ogura H, Koh T, Matsumoto N and Shimazu T: Enhanced expression of cell-specific surface antigens on endothelial microparticles in sepsis-induced disseminated intravascular coagulation. Shock 43: 443-449, 2015.

33. Braach N, Frommhold D, Buschmann K, Pflaum J, Koch L, Hudalla H, Staudacher K, Wang H, Isermann B, Nawroth P, Poeschl J: RAGE controls activation and anti-inflammatory signalling of protein C. PloS One 9: e89422, 2014.

34. Esmon CT: Protein C anticoagulant system--anti-inflammatory effects. Semin Immunopathol 34: 127-132, 2012.

35. Gires O, Kieu C, Fix P, Schmitt B, Münz M, Wollenberg B and Zeidler R: Tumor necrosis factor alpha negatively regulates the expression of the carcinoma-associated antigen epithelial cell adhesion molecule. Cancer 92: 620-628, 2001.

36. Ravi R, Mookerjee B, van Hensbergen Y, Bedi GC, Giordano A, El-Deiry WS, Fuchs EJ and Bedi A: p53-mediated repression of nuclear factor-kappaB RelA via the transcriptional integrator p300. Cancer Res 58: 4531-4536, 1998.

37. Wang Y, Li C, Cheng K, Cheng K, Zhang R, Narsinh K, Li S, Li X, Qin X, Zhang R, Li C, et al: Activation of liver X receptor improves viability of adipose-derived mesenchymal stem cells to attenuate myocardial ischemia injury through TLR4/NF- $\mathrm{B}$ and Keap-1/Nrf-2 signaling pathways. Antioxid Redox Signal 21: 2543-2557, 2014.

38. Kaur U, Banerjee P, Bir A, Sinha M, Biswas A and Chakrabarti S Reactive oxygen species, redox signaling and neuroinflammation in alzheimer's disease: The NF-кB connection. Curr Top Med Chem 15:446-457, 2015.

39. Drdová B and Vachtenheim J: A role for p21 (WAF1) in the cAMP-dependent differentiation of F9 teratocarcinoma cells into parietal endoderm. Exp Cell Res 304: 293-304, 2005.

40. Ishii H, Horie S, Kizaki K and Kazama M: Retinoic acid counteracts both the downregulation of thrombomodulin and the induction of tissue factor in cultured human endothelial cells exposed to tumor necrosis factor. Blood 80: 2556-2562, 1992.
41. Koga S, Morris S, Ogawa S, Liao H, Bilezikian JP, Chen G, Thompson WJ,AshikagaT,BrettJ,SternDM, et al:TNFmodulates endothelial properties by decreasing cAMP Am J Physiol 268: C1104-C1113, 1995

42. Goligorsky MS, Chen J and Brodsky S: Workshop: Endothelial cell dysfunction leading to diabetic nephropathy: Focus on nitric oxide. Hypertension 37: 744-748, $2003 \S 1$.

43. Brownlee M: Biochemistry and molecular cell biology of diabetic complications. Nature 414: 813-820, 2001.

44. Endemann DH and Schiffrin EL: Endothelial dysfunction. J Am Soc Nephrol 15: 1983-1992, 2004.

45. Murata I, Takemura G, Asano K, Sano H, Fujisawa K, Kagawa T, Baba K, Maruyama R, Minatoguchi S, Fujiwara T and Fujiwara H: Apoptotic cell loss following cell proliferation in renal glomeruli of Otsuka Long-Evans Tokushima Fatty rats, a model of human type 2 diabetes. Am J Nephrol 22: 587-595, 2002.

46. Kumar D, Robertson S and Burns KD: Evidence of apoptosis in human diabetic kidney. Mol Cell Biochem 259: 67-70, 2004.

47. Baba K, Minatoguchi S, Sano H, Kagawa T, Murata I, Takemura G, Hirano T, Ohashi H, Takemura M, Fujiwara T: Involvement of apoptosis in patients with diabetic nephropathy: A study on plasma soluble Fas levels and pathological findings. Nephrology (Carlton) 9: 94-99, 2004.

48. Esmon CT: Inflammation and the activated protein $\mathrm{C}$ anticoagulant pathway. Semin Thromb Hemost 32 (Suppl 1): 49-60, 2006.

49. Borcea V, Morcos M, Isermann B, Henkels M, Ziegler S, Zumbach M, Amiral J, Längst KD, Seiz W, Ziegler R, et al: Influence of ramipril on the course of plasma thrombomodulin in patients with diabetes mellitus. Vasa 28: 172-180, 1999.

50. Fujiwara Y, Tagami S and Kawakami Y: Circulating thrombomodulin and hematological alterations in type 2 diabetic patients with retinopathy. J Atheroscler Thromb 5: 21-28, 1998.

51. Rajashekhar G, Gupta A, Marin A, Friedrich J, Willuweit A, Berg DT, Cramer MS, Sandusky GE, Sutton TA, Basile DP, et al: Soluble thrombomodulin reduces inflammation and prevents microalbuminuria induced by chronic endothelial activation in transgenic mice. Am J Physiol Renal Physiol 302: F703-F712, 2012.

52. Pruna A, Peyri N, Berard M and Boffa MC: Thrombomodulin is synthesized by human mesangial cells. Kidney Int 51: 687-693, 1997.

53. Rasmussen LM, Schmitz O and Ledet T: Increased expression of vascular cell adhesion molecule-1 (VCAM-1) in cultured endothelial cells exposed to serum from type 1 diabetic patients: No effects of high glucose concentrations. Scand J Clin Lab Invest 62: 485-493, 2002.

54. Janowski BA, Willy PJ, Devi TR, Falck JR and Mangelsdorf DJ: An oxysterol signalling pathway mediated by the nuclear receptor LXR alpha. Nature 383: 728-731, 1996.

55. Fiévet C and Staels B: Liver X receptor modulators: Effects on lipid metabolism and potential use in the treatment of atherosclerosis. Biochem Pharmacol 77: 1316-1327, 2009. 